\title{
Anti - fuzzy AT - ideals of AT - algebras
}

\section{Areej Tawfeeq Hameed Ahmed Hamza Abed Baieda Hassan Hadi Department of Mathematics, Faculty of Education for Girls, University of Kufa, Iraq. E-mail: areej.tawfeeq@uokufa.edu.iq or areej238@gmail.com}

DOI: $10.29304 / j q c m .2018 .10 .3 .406$

\begin{abstract}
.
In this paper, we introduce the notion of anti - fuzzy AT - ideals in AT - algebra, several appropriate examples are provided and theirsome properties are investigated. The image and the inverse imageof anti-fuzzy AT - ideals in AT-algebra are defined and how theimage and the inverse image of anti-fuzzy AT-ideals in AT-algebra become anti-fuzzy AT-ideals are studied. Moreover, the Cartesian product of anti-fuzzy AT - ideals are given .
\end{abstract}

Keywords : AT - ideal, anti - fuzzy AT - ideals, image and pre-image of anti - fuzzy AT - ideals .

Mathematics subject classification: 06F35, 03G25, 08A72. 
Areej .T/Ahmed .H/Baieda .H

\section{Introduction}

BCK - algebras form an important class of logical algebras introducedby $\mathrm{K}$. Iseki [4] and was extensively investigated by several researchers. Theclass of all BCK - algebras is quasi variety. J. Meng and Y. B. Jun posed an interesting problem (solved in[7]) whether the class of all BCK - algebras is a variety. In connection with this problem , Komori introduced in [6] notion of BCC-algebras. W.A. Dudek (cf.[2],[5]) redefined the notion of BCC - algebras by using a dual form of the ordinary definition inthe sense of Y. Komori and studied ideals and congruences of BCC-algebras. In ([10],[11]), C. Prabpayak and U. Leerawat introduced a new algebraic structure, which is called $\mathrm{KU}-$ algebra. They gave the concept of homomorphisms of $\mathrm{KU}$ - algebras and investigated some related properties. L.A. Zadeh [13] introduced the notion of fuzzy sets. At present this concept has been applied to many mathematical branches, such as group, functional analysis, probability theory, topology, and soon. In 1991 , O.G. Xi [12] applied this concept to BCK algebras, and heintroduced the notion of fuzzy subalgebras (ideals) of the BCK - algebras with respect to minimum, and since then Jun et al studiedfuzzy ideals (cf.[1],[5],[12]), and moreover several fuzzystructures in BCC-algebras are considered (cf.[2],[6]). S. Mostafa , M. AbdElnaby, F. Abdel-Halim and A.T. Hameed (in [7]) introduced the notion of fuzzy KUS - ideals of KUS - algebras and they investigated severalbasic properties which are related to fuzzy KUS - ideals. they describedhow to deal with the homomorphism image and inverse image of fuzzy KUS - ideals. And in [8], the anti - fuzzy KUS - ideals of KUS - algebras is introduced. Several theorems are stated and proved. In [3], Areej Tawfeeq Hameed introduced and studied new algebraic structure, called AT algebra and investigate some of its properties. She introduced the notion of fuzzy AT - ideal of AT-algebra, several theorems, properties are stated and proved.

In this paper, we introduce the notion of antifuzzy AT - ideals of AT - algebras and then we study the homomorphism image and inverse image of anti - fuzzy

AT - ideals. We also prove that the Cartesian product of anti - fuzzy AT - ideals are anti - fuzzy AT ideals .

\section{Preliminaries}

In this section we give some basic definitions and preliminaries lemmas of AT - ideals and fuzzy AT - ideals of AT - algebra.

Definition 2.1[3]. An AT-algebra is a nonempty set $\mathrm{X}$ with a constant ( 0 ) and a binary operation $(*)$ satisfying the following axioms: for all $\mathrm{x}, \mathrm{y}, \mathrm{z} \in \mathrm{X}$,

(i) $(\mathrm{x} * \mathrm{y}) *((\mathrm{y} * \mathrm{z}) *(\mathrm{x} * \mathrm{z}))=0$,

(ii) $0^{*} \mathrm{x}=\mathrm{x}$,

(iii) $\quad \mathrm{x}^{*} 0=0$.

In $\mathrm{X}$ we can define a binary relation $(\leq)$ by $: x \leq y$ if and only if, $y^{*} x=0$.

Remark 2.2[3]. (X ;*, 0) is an AT - algebra if and only if, it satisfies that: for allx, $y, z \in X$,

(i') : $(\mathrm{y} * \mathrm{z}) *(\mathrm{x} * \mathrm{z}) \leq \mathrm{x} * \mathrm{y}$,

(ii') : $\mathrm{x} \leq \mathrm{y}$ if and only if, $\mathrm{y} * \mathrm{x}=0$.

Example 2.3 [3]. Let $X=\{0,1,2,3,4\}$ in which $(*)$ is defined by the following table:

\begin{tabular}{|c|r|r|r|r|r|}
\hline$*$ & 0 & 1 & 2 & 3 & 4 \\
\hline 0 & 0 & 1 & 2 & 3 & 4 \\
\hline 1 & 0 & 0 & 2 & 3 & 4 \\
\hline 2 & 0 & 1 & 0 & 3 & 3 \\
\hline 3 & 0 & 0 & 2 & 0 & 2 \\
\hline 4 & 0 & 0 & 0 & 0 & 0 \\
\hline
\end{tabular}

It is easy to show that $(\mathrm{X} ; *, 0)$ is an AT - algebra. Example 2.4[3]. Let $X=\{0,1,2,3,4\}$ be a set with the following table:

\begin{tabular}{|c|c|c|c|c|c|}
\hline$*$ & 0 & 1 & 2 & 3 & 4 \\
\hline 0 & 0 & 1 & 2 & 3 & 4 \\
\hline 1 & 0 & 0 & 2 & 3 & 4 \\
\hline 2 & 0 & 1 & 0 & 3 & 3 \\
\hline 3 & 0 & 0 & 2 & 0 & 2 \\
\hline 4 & 0 & 0 & 0 & 0 & 0 \\
\hline
\end{tabular}

Then $(\mathrm{X} ; *, 0)$ is an AT - algebra.

Proposition 2.5 [3]. In any AT - algebra (X $\left.;^{*}, 0\right)$, the following properties holds: for all $\mathrm{x}, \mathrm{y}, \mathrm{z}$ $\in \mathrm{X}$;
a) $\mathrm{z} * \mathrm{z}=0$
b) $\mathrm{z} *(\mathrm{x} * \mathrm{z})=0$
c) $\mathrm{y} *((\mathrm{y} * \mathrm{z}) * \mathrm{z})=0$,
d) $\mathrm{x} * \mathrm{y}=0$ implies that $\mathrm{x} * 0=\mathrm{y} * 0$,
e) $\quad 0 * x=0 * y$ implies that $\mathrm{x}=\mathrm{y}$. 
Proposition 2.6[3]. In any AT - algebra $(\mathrm{X} ; *$, $0)$, the following properties holds: for all $\mathrm{x}, \mathrm{y}, \mathrm{z}$ $\in \mathrm{X}$;

a) $\mathrm{x} \leq \mathrm{y}$ implies that $\mathrm{y} * \mathrm{z} \leq \mathrm{x} * \mathrm{z}$,

b) $\mathrm{x} \leq \mathrm{y}$ implies that $\mathrm{z} * \mathrm{x} \leq \mathrm{z} * \mathrm{y}$

c) $\mathrm{z} * \mathrm{x} \leq \mathrm{z} * \mathrm{y}$ implies that $\mathrm{x} \leq \mathrm{y}$ ( left cancellation law).

Proposition 2.7[3]. In any AT - algebra (X ;*, 0 ), the following properties holds: for all $\mathrm{x}, \mathrm{y}, \mathrm{z} \in \mathrm{X}$;

a) $\mathrm{x}=0 *(0 * \mathrm{x})$,

b) $\mathrm{x}^{*} \mathrm{y} \leq \mathrm{z}$ imply $\mathrm{z} * \mathrm{y} \leq \mathrm{x}$.

Definition 2.8[3]. A nonempty subset $S$ of an AT - algebra $X$ is called an AT - subalgebra of AT - algebra $X$ if $x^{*} y \in S$, whenever $\mathrm{x}, \mathrm{y} \in \mathrm{S}$.

Definition 2.9[3]. A nonempty subset I of an AT - algebra $X$ is called an AT-ideal of ATalgebra $\mathbf{X}$ if it satisfies the following conditions: for all $\mathrm{x}, \mathrm{y}, \mathrm{z} \in \mathrm{X}$.

$\left.\mathrm{AT}_{1}\right) 0 \in \mathrm{I}$;

$\left.\mathrm{AT}_{2}\right) \mathrm{x} *(\mathrm{y} * \mathrm{z}) \in \mathrm{I}$ and $\mathrm{y} \in \mathrm{I}$ imply $\mathrm{x} * \mathrm{z} \in \mathrm{I}$.

Proposition 2.10[3]. Every AT - ideal of AT - algebra X is an AT - subalgebra.

Definition 2.11[3]. Let $X$ be an AT - algebra.

A fuzzy set $\mu$ in $\mathrm{X}$ is called a fuzzy AT subalgebra of $\mathrm{X}$ if it satisfies the following conditions: for all $\mathrm{x}, \mathrm{y} \in \mathrm{X}$, $\mu(\mathrm{x} * \mathrm{y}) \geq \min \{\mu(\mathrm{x}), \mu(\mathrm{y})\}$.

Definition 2.12[3]. Let X be an AT - algebra. A fuzzy set $\mu$ in $\mathrm{X}$ is called a fuzzy AT - ideal of $\mathrm{X}$ if it satisfies the following conditions: for all $\mathrm{x}, \mathrm{y}$ and $\mathrm{z} \in \mathrm{X}$,

$$
\begin{aligned}
& \left(\mathrm{AT}_{1}\right) \mu(0) \geq \mu(\mathrm{x}) . \\
& \left(\mathrm{AT}_{2}\right) \mu(\mathrm{x} * \mathrm{z}) \geq \min \{\mu(\mathrm{x} *(\mathrm{y} * \mathrm{z})), \mu(\mathrm{y})\} .
\end{aligned}
$$

Proposition 2.13[3]. Every fuzzy AT - ideal of AT - algebra X is fuzzy AT - subalgebra.

\section{Anti-fuzzy AT-ideals of AT-algebras}

In this section, we will introduce a new notion called an anti - fuzzy AT - ideal of AT - algebra and study several basic properties of it.
Definition 3.1[13]. Let $\mathrm{X}$ be a nonempty set, a fuzzy set $\mu$ in $X$ is a function $\mu: X \rightarrow[0,1]$.

Definition 3.2. Let $\mathrm{X}$ be an AT - algebra. A fuzzy set $\mu$ in $X$ is called an anti-fuzzy AT - ideal of $\mathrm{X}$ if it satisfies the following conditions: for all $\mathrm{x}$, $\mathrm{y}$ and $\mathrm{z} \in \mathrm{X}$,

$$
\begin{aligned}
& \left(\mathrm{AAT}_{1}\right) \mu(0) \leq \mu(\mathrm{x}) . \\
& \left(\mathrm{AAT}_{2}\right) \mu(\mathrm{x} * \mathrm{z}) \leq \max \{\mu(\mathrm{x} *(\mathrm{y} * \mathrm{z})), \mu(\mathrm{y})\} .
\end{aligned}
$$

Example 3.3. Let $X=\{0,1,2,3\}$ be a set with the following table:

\begin{tabular}{|c|c|c|c|c|}
\hline$*$ & 0 & 1 & 2 & 3 \\
\hline 0 & 0 & 1 & 2 & 3 \\
\hline 1 & 0 & 0 & 2 & 3 \\
\hline 2 & 0 & 0 & 0 & 3 \\
\hline 3 & 0 & 0 & 0 & 0 \\
\hline
\end{tabular}

Then $(\mathrm{X} ; *, 0)$ is an AT - algebra. It is easy to show that $I_{1}=\{0,1\}$ and $I_{2}=\{0,3\}$ are AT-ideals of $\mathrm{X}$.

Define a fuzzy set $\mu: X \rightarrow[0,1]$ by $\mu(0)=t_{1}, \mu(1)$

$=\mu(2)=\mu(3)=t_{2}$, where $t_{1}$, $\mathrm{t}_{2} \in[0,1]$

with $\mathrm{t}_{1}<\mathrm{t}_{2}$.

Routine calculation gives that $\mu$ is an anti-

fuzzy AT - ideal of AT - algebras X.

Lemma 3.4. Let $\mu$ be an anti-fuzzy AT - ideal of AT - algebra X and if $x \leq y$, then $\mu(y) \leq \mu(x)$, for all $\mathrm{x}, \mathrm{y} \in \mathrm{X}$.

Proof: Assume that $\mathrm{x} \leq \mathrm{y}$, then $\mathrm{y} * \mathrm{x}=0$, and $\mu(0 * y)=\mu(y) \leq \max \left\{\mu\left(0 *\left(x^{*} y\right)\right), \mu(x)\right\}=\max$ $\{\mu(0), \mu(\mathrm{x})\}=\mu(\mathrm{x})$.

Hence $\mu(\mathrm{y}) \leq \mu(\mathrm{x})$. $\triangle$ 
Proposition 3.5. Let $\mu$ be an anti- fuzzy AT ideal of AT - algebra X. If the inequality $\mathrm{y} * \mathrm{x} \leq \mathrm{z}$ hold in $X$, then $\mu(\mathrm{x}) \leq \max \{\mu(\mathrm{y}), \mu(\mathrm{z})\}$.

Proof: Assume that the inequality $\mathrm{y} * \mathrm{x} \leq \mathrm{z}$ hold in $\mathrm{X}$, by lemma(3.4),

$$
\begin{aligned}
& \mu(\mathrm{z}) \leq \mu(\mathrm{y} * \mathrm{x})---(1) . \\
& \quad \mathrm{By}\left(\mathrm{AAT}_{2}\right), \mu(\mathrm{z} * \mathrm{x}) \leq \max \{\mu(\mathrm{z} *(\mathrm{y} * \mathrm{x})), \mu(\mathrm{y})\} . \text { Put }
\end{aligned}
$$
$\mathrm{z}=0$, then

$\mu(0 * x)=\mu(x) \leq \max \left\{\mu\left(0 *\left(y^{*} x\right)\right), \mu(y)\right\}=\max$

$\{\mu(\mathrm{y} * \mathrm{x}), \mu(\mathrm{y})\}---(2)$.

From (1) and (2), we get $\mu(\mathrm{x}) \leq \max \{\mu(\mathrm{y}), \mu(\mathrm{z})\}$, for all $\mathrm{x}, \mathrm{y}, \mathrm{z} \in \mathrm{X}$. $\triangle$

Theorem 3.6. Let $\mu$ be an anti-fuzzy set in $X$ then $\mu$ is an anti - fuzzy AT - ideal of $X$ if and only if, it satisfies:

For all $\alpha \in[0,1], U(\mu, \alpha) \neq \varnothing$ implies $U(\mu, \alpha)$ is an AT - ideal of X----(A), where $U(\mu, \alpha)=\{x \in X \mid \mu(x) \leq \alpha\}$.

Proof: Assume that $\mu$ is an anti - fuzzy AT ideal of $X$, let $\alpha \in[0,1]$ be such that $\mathrm{U}(\mu, \alpha) \neq \varnothing$, and let $\mathrm{x}, \mathrm{y} \in \mathrm{X}$ be such that $\mathrm{x} \in \mathrm{U}(\mu, \alpha)$, then $\mu(\mathrm{x}) \leq \alpha$ and so by $\left(\mathrm{AAT}_{1}\right), \mu(0) \leq \mu(\mathrm{x}) \leq \alpha$. Thus $0 \in$ $\mathrm{U}(\mu, \alpha)$.

Now let $(\mathrm{z} *(\mathrm{y} * \mathrm{x})), \mathrm{y} \in \mathrm{U}(\mu, \alpha)$. It follows from $\left(\mathrm{AAT}_{2}\right)$ that $\mu(\mathrm{z} * \mathrm{x}) \leq \max \left\{\mu\left(\mathrm{z} *\left(\mathrm{y}^{*} \mathrm{x}\right)\right), \mu(\mathrm{y})\right\}=\alpha$, so that $(\mathrm{z} *$ $\mathrm{x}) \in \mathrm{U}(\mu, \alpha)$. Hence $\mathrm{U}(\mu, \alpha)$ is an AT - ideal of $\mathrm{X}$.

Conversely, suppose that $\mu$ satisfies (A), assume that $\left(\mathrm{AAT}_{1}\right)$ is false, then there exist $\mathrm{x} \in \mathrm{X}$ such that $\mu(0)>\mu(x)$.If we take $t=\frac{1}{2}(\mu(x)+\mu(0))$, then $\mu$ (0) $>$ t and
$0 \leq \mu(\mathrm{x})<\mathrm{t} \leq 1$, thusx $\in \mathrm{U}(\mu, \mathrm{t})$ and $\mathrm{U}(\mu, \mathrm{t}) \neq \varnothing$.As

$\mathrm{U}(\mu, \mathrm{t})$ is an AT - ideal of $\mathrm{X}$, we have $0 \in$ $\mathrm{U}(\mu, \mathrm{t})$, and so $\mu(0) \leq \mathrm{t}$. This is a contradiction. Hence $\mu(0) \leq \mu(\mathrm{x})$ for all $\mathrm{x} \in \mathrm{X}$. Now, assume $\left(\mathrm{AAT}_{2}\right)$ is not true thenthere exist $\mathrm{x}, \mathrm{y}, \mathrm{z} \in \mathrm{X}$ such that $\mu(\mathrm{z} * \mathrm{x})>\max \{\mu(\mathrm{z} *(\mathrm{y} * \mathrm{x})), \mu(\mathrm{y})\}$, taking $\beta_{0}=\frac{1}{2}\left[\mu\left(\mathrm{z}^{*} \mathrm{x}\right)+\max \{\mu(\mathrm{z} *(\mathrm{y} * \mathrm{x})), \mu(\mathrm{y})\}\right]$, we have $\beta_{0} \in[0,1]$ and $\max \left\{\mu\left(\mathrm{z} *\left(\mathrm{y}^{*} \mathrm{x}\right)\right), \mu(\mathrm{y})\right\},<\beta_{0}<\mu(\mathrm{z} * \mathrm{x})$, it follows that $\max \left\{\mu\left(\mathrm{z} *\left(\mathrm{y}^{*} \mathrm{x}\right)\right), \mu(\mathrm{y})\right\}, \in \mathrm{U}\left(\mu, \beta_{0}\right)$ and $\mathrm{z} * \mathrm{y} \notin$ $\mathrm{U}\left(\mu, \beta_{0}\right)$, this is a contradiction and therefore $\mu$ is an anti - fuzzy AT - ideal of X. $\triangle$

\section{Characterization of anti-fuzzy AT-} ideals by their level AT-ideals

Theorem 4.1. A fuzzy subset $\mu$ of an AT algebra $\mathrm{X}$ is an anti - fuzzy AT - ideal of $\mathrm{X}$ if and only if, for every $\mathrm{t} \in[0,1], \mu_{\mathrm{t}}$ is an AT - ideal of $\mathrm{X}$, where

$\mu_{t}=\{x \in X \mid \mu(x) \leq t\}$.

Proof: Assume that $\mu$ is an anti - fuzzy AT ideal of $\mathrm{X}$, by $\left(\mathrm{AAT}_{1}\right)$, we have $\mu(0) \leq \mu(\mathrm{x})$ for all $\mathrm{x} \in \mathrm{X}$, therefore $\mu(0) \leq \mu(\mathrm{x}) \leq \mathrm{t}$, for $\mathrm{x} \in \mu_{\mathrm{t}}$ and so $0 \in \mu_{\mathrm{t}}$.

Let $\left(\mathrm{z} *\left(\mathrm{y}^{*} \mathrm{x}\right)\right) \in \mu_{\mathrm{t}}$ and $(\mathrm{y}) \in \mu_{\mathrm{t}}$, then $\mu\left(\mathrm{z}^{*}\left(\mathrm{y}^{*} \mathrm{x}\right)\right) \leq \mathrm{t}$ and $\mu(\mathrm{y}) \leq \mathrm{t}$,since $\mu$ is an anti - fuzzy AT - ideal it follows that $\mu(\mathrm{z} * \mathrm{x}) \leq\left\{\mu\left(\mathrm{z} *\left(\mathrm{y}^{*} \mathrm{x}\right)\right), \mu(\mathrm{y})\right\} \leq \mathrm{t}$ and that 
$(\mathrm{z} * \mathrm{x}) \in \mu_{\mathrm{t}}$. Hence $\mu_{\mathrm{t}}$ is an AT - ideal of $\mathrm{X}$.

Conversely, we only need to show that $\left(\mathrm{AAT}_{1}\right)$ and $\left(\mathrm{AAT}_{2}\right)$ are true. If $\left(\mathrm{AAT}_{1}\right)$ is false, then there exist $\mathrm{x} \in$ Xsuch that $\mu(0)>\mu(\mathrm{x})$. If we take $\mathrm{t}=\frac{1}{2}(\mu(\mathrm{x})$ $+\mu(0))$, then $\mu(0)>t$ and $0 \leq \mu(x)<t \leq 1$ thus $x \in$ $\mu_{t}$ and $\mu_{t} \neq \varnothing$. As $\mu_{t}$ is an AT - ideal of $X$, we have $0 \in \mu_{\mathrm{t}}$ and so $\mu(0) \leq \mathrm{t}$. This is a contradiction. Now,assume $\left(\mathrm{AAT}_{2}\right)$ is not true, then there exist $\mathrm{x}$, $\mathrm{y}$ and $\mathrm{z} \in \mathrm{Xsuch}$ that,

$\mu\left(\mathrm{z}^{*} \mathrm{x}\right)>\max \left\{\mu\left(\mathrm{z}^{*}\left(\mathrm{y}^{*} \mathrm{x}\right)\right), \mu(\mathrm{y})\right\}$.

Putting $\mathrm{t}=\frac{1}{2}[\mu(\mathrm{z} * \mathrm{x})+\max \{\mu(\mathrm{z} *(\mathrm{y} * \mathrm{x})), \mu(\mathrm{y})\}]$, then $\mu(z * x)>t$ and

$0 \leq \max \left\{\mu\left(\mathrm{z} *\left(\mathrm{y}^{*} \mathrm{x}\right)\right), \mu(\mathrm{y})\right\},<\mathrm{t} \leq 1$, hence $\mu(\mathrm{z} *$ $\left.\left(\mathrm{y}^{*} \mathrm{x}\right)\right)<\mathrm{t}$ and $\mu(\mathrm{y})<\mathrm{t}$, which imply that $(\mathrm{z} * \mathrm{y}) \in \mu_{\mathrm{t}}$ $\operatorname{and}(y * x) \in \mu_{t}$, since $\mu_{\mathrm{t}}$ is an anti - fuzzy AT ideal, it follows that $(\mathrm{z} * \mathrm{x}) \in \mu_{\mathrm{t}}$ and that $\mu(\mathrm{z} * \mathrm{x}) \leq$ $\mathrm{t}$, this is also a contradiction. Hence $\mu$ is an anti fuzzy AT - ideal of X . $\triangle$

Corollary 4.2. If a fuzzy subset $\mu$ of AT algebra $\mathrm{X}$ is an anti - fuzzy AT - ideal, then for every $t \in \operatorname{Im}(\mu), \mu_{t}$ is an AT - ideal of $X$.

Definition 4.3. Let $\mu$ be an anti - fuzzy AT ideal of AT - algebra X, then the AT - ideal $\mu_{t}, t$ $\in[0,1]$ are called level AT - ideals of $\mu$.

Corollary 4.4. Let I be an AT - ideal of an AT - algebra $X$, then for any fixed number $t$ in an open interval $(0,1)$, there existan anti - fuzzy AT ideal $\mu$ of $X$ such that $\mu_{t}=I$.
Proof: Define $\mu: X \rightarrow[0: 1]$ by $\mu(\mathrm{x})=$

$\left\{\begin{array}{cl}0, & \text { if } \mathrm{x} \in \mathrm{I} \\ \mathrm{t}, & \text { if } \mathrm{x} \notin \mathrm{I} .\end{array}\right.$

Where $\mathrm{t}$ is a fixed number in $(0,1)$. Clearly, $\mu(0) \leq \mu$

(x) and we have one two level sets $\mu_{0}=I, \mu_{t}=X$, which are AT - ideals of X, then from Theorem (4.1) $\mu$ is an anti - fuzzy AT - ideal of X. $\triangle$

\section{Image and Pre-image of anti-fuzzy}

\section{AT-ideals}

Definition 5.1. $f:(\mathrm{X} ; *, 0) \rightarrow\left(\mathrm{Y} ; *^{*}{ }^{`}, 0^{`}\right)$ be a mapping from a nonempty set $\mathrm{X}$ to a nonemptyset $Y$. If $\beta$ is a fuzzy subset of $X$, then the fuzzy subset $\mu$ of $\mathrm{Y}$ defined by: $f(\mu)(\mathrm{y})=\beta(\mathrm{y})=$

$$
\left\{\begin{array}{l}
\inf _{x \in f^{-1}(y)} \mu(x) \quad \text { if } f^{-1}(y)=\{x \in X, f(x)=y\} \neq \phi \\
0 \quad \text { otherwise }
\end{array}\right.
$$

is said to be the image of $\mu$ under $f$.

Similarly if $\mu$ is a fuzzy subset of $Y$, then the fuzzy subset $\mu=(\beta o f)$ in $\mathrm{X}$ (i.e., the fuzzy subset defined by $\mu(\mathrm{x})=\beta(f(\mathrm{x}))$, for all $\mathrm{x} \in \mathrm{X})$ is called the pre-image of $\beta$ under $f$.

Theorem 5.2. An into homomorphic preimage of anti - fuzzy AT - ideal is also an anti - fuzzy AT - ideal. 
Proof: Let $f:(\mathrm{X} ; *, 0) \rightarrow\left(\mathrm{Y} ; *^{`}, 0 `\right)$ be an onto homomorphism of AT - algebras, $\beta$ is an anti - fuzzy AT - ideal of $\mathrm{Y}$ and $\mu$ the pre-image of $\beta$ under $f$, then

$\beta(f(\mathrm{x}))=\mu(\mathrm{x})$, for all $\mathrm{x} \in \mathrm{X}$. Let $\mathrm{x} \in \mathrm{X}$, then $\mu(0)$

$=\beta(f(0))<\beta(f(\mathrm{x}))=\mu(\mathrm{x})$.

Now let $\mathrm{x}, \mathrm{y}, \mathrm{z} \in \mathrm{X}$, then $\mu(\mathrm{z} * \mathrm{x})=\beta(f(\mathrm{z} * \mathrm{x}))$ $=\beta\left(f(\mathrm{z}) *{ }^{\prime} f(\mathrm{x})\right)$

$\leq \max \left\{\beta\left(f(\mathrm{z}) *^{\prime} f(\mathrm{y})\right), \beta\left(f(\mathrm{y}) *^{\prime} f(\mathrm{x})\right)\right\}$

$=\max \{\beta(f(\mathrm{z} * \mathrm{y})), \beta(f(\mathrm{y} * \mathrm{x}))\}$

$=\max \{\mu(\mathrm{z} * \mathrm{y}), \mu(\mathrm{y} * \mathrm{x})\}$, and the proof is completed. $\triangle$

Definition 5.3. An anti fuzzy subset $\mu$ of $X$ has inf property if for any subset $\mathrm{T}$ of $\mathrm{X}$, there exist $\mathrm{t}_{0} \in \mathrm{T}$ such that $\mu(\mathrm{t})=\inf _{\mathrm{t} \in \mathrm{T}} \mu(\mathrm{t})$.

Theorem 5.4. Let $f:(\mathrm{X} ; *, 0) \rightarrow\left(\mathrm{Y} ; *^{*}{ }^{`}, 0^{\circ}\right)$ be a homomorphism between AT - algebras X and Y respectively . For every anti - fuzzy AT - ideal $\mu$ in X, $f(\mu)$ is an anti - fuzzy AT - ideal of Y.

Proof: By definition $\beta\left(y^{\prime}\right)=f(\mu)\left(y^{\prime}\right)=$ $\inf _{x \in f^{-1}\left(y^{\prime}\right)} \mu(x)$, for all $y^{\prime} \in Y$ and $\varnothing=0$.

We have to prove that $\beta\left(\mathrm{z}^{\prime} * \mathrm{x}^{\prime}\right) \leq \max \left\{\beta\left(\mathrm{z}^{\prime} *\right.\right.$ $\left.\left.\left(\mathrm{y}^{\prime *} \mathrm{x}^{\prime}\right)\right), \beta\left(\mathrm{y}^{\prime}\right)\right\}$, for all $\mathrm{x}^{\prime}, \mathrm{y}^{\prime}, \mathrm{z}^{\prime} \in \mathrm{Y}$.

Let $f: \mathrm{X} \rightarrow \mathrm{Y}$ be an onto homomorphism of $\mathrm{AT}-$ algebras, $\mu$ is an anti - fuzzy AT - ideal of $\mathrm{X}$ with inf property and $\beta$ the image of $\mu$ under $f$, since $\mu$ is anti - fuzzy AT - ideal of X, we have $\mu(0) \leq \mu$ (x) for all $\mathrm{x} \in \mathrm{X}$.

Note that $0 \in f^{-1}\left(0^{\prime}\right)$, where $0,0^{\prime}$ are the zero of $\mathrm{X}$ and $\mathrm{Y}$, respectively.
Thus $\beta\left(0^{\prime}\right)=\inf _{t \in f^{-1}\left(x^{\prime}\right)} \mu(t)=\beta\left(x^{\prime}\right)$, for all $x \in X$,

which implies that

$\beta\left(0^{\prime}\right) \leq \inf { }_{t \in f^{-1}\left(x^{\prime}\right)} \mu(t)=\beta\left(x^{\prime}\right)$, for any $x^{\prime} \in$ Y.For

any $\mathrm{x}^{\prime}, \mathrm{y}^{\prime}, \mathrm{z}^{\prime} \in \mathrm{Y}$, let $\mathrm{x}_{0} \in f^{-1}\left(\mathrm{x}^{\prime}\right)$,

$\mathrm{y}_{0} \in f^{-1}\left(\mathrm{y}^{\prime}\right), \mathrm{z}_{0} \in f^{-1}\left(\mathrm{z}^{\prime}\right)$ be such that

$\mu\left(\mathrm{z}_{0} *\left(\mathrm{y}_{0} * \mathrm{x}_{0}\right)\right)=\inf _{t \in f^{-1}\left(z^{\prime *}\left(y^{*} x^{\prime}\right)\right)} \mu(t), \mu\left(\mathrm{y}_{0}\right)=$

$\inf _{t \in f^{-1}\left(y^{\prime}\right)} \mu(t)$ and

$\mu\left(\mathrm{z}_{0} * \mathrm{x}_{0}\right)=\mathrm{inf}_{\mathrm{t} \in \mathrm{f}^{-1}\left(\mathrm{z}^{*} \mathrm{x}^{\prime}\right)} \mu(\mathrm{t})$. Then

$\beta\left(\mathrm{z}^{\prime} * \mathrm{x}^{\prime}\right)=\inf _{\mathrm{t} \in \mathrm{f}^{-1}\left(\mathrm{z}^{\prime *} \mathrm{x}^{\prime}\right)} \mu(\mathrm{t})=\mu\left(\mathrm{z}_{0} * \mathrm{x}_{0}\right)$

$\leq \max \left\{\mu\left(\mathrm{z}_{0} *\left(\mathrm{y}_{0} * \mathrm{x}_{0}\right)\right), \mu\left(\mathrm{y}_{0}\right)\right\}$

$=\max \left[\inf _{t \in f^{-1}\left(z^{* *}\left(y^{\prime *} x^{\prime}\right)\right)} \mu(t), \inf _{t \in f^{-1}\left(y^{\prime}\right)} \mu(t)\right]$

$=\max \left\{\beta\left(\mathrm{z}^{\prime} *\left(\mathrm{y}^{\prime *} \mathrm{x}^{\prime}\right)\right), \beta\left(\mathrm{y}^{\prime}\right)\right\}$.

Hence $\beta$ is an anti - fuzzy AT - ideal of Y. $\triangle$

\section{Cartesian product of anti-fuzzy AT-}

\section{ideals}

Definition $6.1([1],[9])$. A fuzzy relation R on any set $\mathrm{S}$ is a fuzzy subset

$\mathrm{R}: \mathrm{S} \times \mathrm{S} \rightarrow[0,1]$.

Definition 6.2 ([1]). If $\mathrm{R}$ is a fuzzy relation on sets $S$ and $\beta$ is a fuzzy subset of $S$, then Ris a fuzzy relation on $\beta$ if $\mathrm{R}(\mathrm{x}, \mathrm{y}) \geq \max \{\beta(\mathrm{x})$, $\beta(y)\}$, for all $x, y \in S$.

Definition 6.3([1]). Let $\mu$ and $\beta$ be fuzzy subsets of a set $\mathrm{S}$. The Cartesian product of $\mu$ and $\beta$ is defined by $(\mu \times \beta)(x, y)=\max \{\mu(x), \beta(y)\}$, for all $x, y \in S$. 
Lemma 6.4([1]). Let $\mathrm{S}$ be a set and $\mu$ and $\beta$ be fuzzy subsets of $S$. Then,

(1) $\mu \times \beta$ is a fuzzy relation on $S$,

(2) $(\mu \times \beta)_{t}=\mu_{t} \times \beta_{t}$, for all $t \in[0,1]$.

Definition 6.5([1]). Let $S$ be a set and $\beta$ be fuzzy subset of $\mathrm{S}$. The strongest fuzzy relation on $\mathrm{S}$, that is, a fuzzy relation on $\beta$ is $\mathrm{R}_{\beta}$ given by $\mathrm{R}_{\beta}(\mathrm{x}, \mathrm{y})=\max \{\beta(\mathrm{x}), \beta(\mathrm{y})\}$, for all $\mathrm{x}, \mathrm{y} \in \mathrm{S}$.

Lemma 6.6([1]). For a given fuzzy subset $\beta$ of a set $S$, let $R_{\beta}$ be the strongest fuzzy relation on $S$.

Then for $\mathrm{t} \in[0,1]$, we have $\left(\mathrm{R}_{\beta}\right)_{t}=\beta_{\mathrm{t}} \times \beta_{\mathrm{t}}$.

Proposition 6.7. For a given fuzzy subset $\beta$ of an $\mathrm{AT}$ - algebra $\mathrm{X}$, let $\mathrm{R}_{\beta}$ be the strongest fuzzy relation on $X$. If $\beta$ is an anti - fuzzy AT ideal of $\mathrm{X} \times \mathrm{X}$, then

$\mathrm{R}_{\beta}(\mathrm{x}, \mathrm{x}) \geq \mathrm{R}_{\beta}(0,0)$, for all $\mathrm{x} \in \mathrm{X}$.

Proof: Since $R_{\beta}$ is a strongest fuzzy relation of $\mathrm{X} \times \mathrm{X}$, it follows from that,

$\mathrm{R}_{\beta}(\mathrm{x}, \mathrm{x})=\max \{\beta(\mathrm{x}), \beta(\mathrm{x})\} \geq \max \{\beta(0), \beta(0)\}=\mathrm{R}_{\beta}$ $(0,0)$, which implies that

$\mathrm{R}_{\beta}(\mathrm{x}, \mathrm{x}) \geq \mathrm{R}_{\beta}(0,0)$.

Proposition 6.8. For a given fuzzy subset $\beta$ of an AT - algebra $X$, let $R_{\beta}$ be the strongest fuzzy relation on $X$. If $R_{\beta}$ is an anti - fuzzy AT ideal of $\mathrm{X} \times \mathrm{X}$, then $\beta(0) \leq \beta(x)$, for all $x \in X$.
Proof: Since $R_{\beta}$ is an anti - fuzzy AT - ideal of $\mathrm{X} \times \mathrm{X}$, it follows from $\left(\mathrm{AAT}_{1}\right)$, $R_{\beta}(x, x) \geq R_{\beta}(0,0)$, where $(0,0)$ is the zero element of $X \times X$. But this means that $\max \{\beta(\mathrm{x}), \beta(\mathrm{x})\} \geq$ $\max \{\beta(0), \beta(0)\}$ which implies that $\beta(0) \leq \beta(x)$. $\triangle$

Remark 6.9([9]). Let X and Y be AT algebras, we define $(*)$ on $\mathrm{X} \times \mathrm{Y}$ by: for all $(\mathrm{x}, \mathrm{y}),(\mathrm{u}, \mathrm{v}) \in \mathrm{X} \times \mathrm{Y},(\mathrm{x}, \mathrm{y}) *(\mathrm{u}, \mathrm{v})=(\mathrm{x} * \mathrm{u}, \mathrm{y} * \mathrm{v})$. Then clearly $(\mathrm{X} \times \mathrm{Y} ; * .(0,0))$ is anAT-algebra.

Theorem 6.10. Let $\mu$ and $\beta$ be an anti fuzzy AT - ideal of AT - algebra $X$. Then $\mu \times \beta$ is an anti - fuzzy AT - ideal of $\mathrm{X} \times \mathrm{X}$.

Proof: Note first that for every $(\mathrm{x}, \mathrm{y}) \in \mathrm{X} \times \mathrm{X}$, $(\mu \times \beta)(0,0)=\max \{\mu(0), \beta(0)\} \leq \max \{\mu(x)$, $\beta(\mathrm{y})\}=(\mu \times \beta)(\mathrm{x}, \mathrm{y})$.

Now let $\left(\mathrm{x}_{1}, \mathrm{x}_{2}\right),\left(\mathrm{y}_{1}, \mathrm{y}_{2}\right),\left(\mathrm{z}_{1}, \mathrm{z}_{2}\right) \in \mathrm{X} \times \mathrm{X}$. Then $(\mu \times \beta)\left(x_{1} * z_{1}, x_{2} * z_{2}\right)=\max \left\{\mu\left(x_{1} * z_{1}\right), \beta\left(x_{2}\right.\right.$ $\left.\left.* \mathrm{z}_{2}\right)\right\}$

$\leq \max \left\{\max \left\{\mu\left(\mathrm{x}_{1} *\left(\mathrm{y}_{1} * \mathrm{z}_{1}\right)\right), \mu\left(\mathrm{y}_{1}\right)\right\}, \max \left\{\beta\left(\mathrm{x}_{2}\right.\right.\right.$ $\left.\left.\left.*\left(\mathrm{y}_{2} * \mathrm{z}_{2}\right)\right), \beta\left(\mathrm{y}_{2}\right)\right\}\right\}$

$=\max \left\{\max \left\{\mu\left(\left(\mathrm{x}_{1} *\left(\mathrm{y}_{1} * \mathrm{z}_{1}\right)\right)\right), \beta\left(\mathrm{x}_{2} *\left(\mathrm{y}_{2} *\right.\right.\right.\right.$

$\left.\left.\left.\left.\mathrm{z}_{2}\right)\right)\right\}, \max \left\{\mu\left(\mathrm{y}_{1}\right), \beta\left(\mathrm{y}_{2}\right)\right\}\right\}$

$$
=\max \left\{( \mu \times \beta ) \left(\left(\mathrm{x}_{1} *\left(\mathrm{y}_{1} * \mathrm{z}_{1}\right)\right),\left(\mathrm { x } _ { 2 } * \left(\mathrm{y}_{2} *\right.\right.\right.\right.
$$

$\left.\left.\left.\left.\mathrm{z}_{2}\right)\right)\right),(\mu \times \beta)\left(\mathrm{y}_{1}, \mathrm{y}_{2}\right)\right\}$

Hence $(\mu \times \beta)$ is an anti - fuzzy AT - ideal of $\mathrm{X} \times \mathrm{X} \cdot \bullet$

Theorem 6.11. Let $\mu$ and $\beta$ be anti-fuzzy subsets of AT - algebra $X$ such that $\mu \times \beta$ is an anti - fuzzy AT - ideal of $X \times X$. Then for all $\mathrm{x} \in \mathrm{X}$,

(i) either $\mu(0) \leq \mu(\mathrm{x})$ or $\beta(0) \leq \beta(\mathrm{x})$. 
(ii) $\mu(0) \leq \mu(\mathrm{x})$ for all $\mathrm{x} \in \mathrm{X}$, then either $\beta(0) \leq$ $\beta(\mathrm{x})$ or $\beta(0) \leq \mu(\mathrm{x})$.

(iii)

$$
\text { If } \beta(0) \leq
$$

$\beta$ (x)for all $x \in X$, then either $\mu(0) \leq$ $\mu(\mathrm{x})$ or $\mu(0) \leq \beta(\mathrm{x})$.

(iv) Either $\mu$ or $\beta$ is an anti - fuzzy AT ideal of $\mathrm{X}$.

\section{Proof.}

(i) Suppose that $\mu(0)>\mu(\mathrm{x})$ and $\beta(0)>\beta(y)$ for some $x, y \in X$. Then

$(\mu \times \beta)(\mathrm{x}, \mathrm{y})=\max \{\mu(\mathrm{x}), \beta(\mathrm{y})\}<\max \{\mu(0)$, $\beta(0)\}=(\mu \times \beta)(0,0)$. This is a contradiction and we obtain (i).

(ii) Assume that there exist $\mathrm{x}, \mathrm{y} \in \mathrm{X}$ such that $\beta(0)$ $>\mu(\mathrm{x})$ and $\beta(0)>\beta(y)$. Then

$(\mu \times \beta)(0,0)=\max \{\mu(0), \beta(0)\}=\beta(0)$ it follows that

$(\mu \times \beta)(\mathrm{x}, \mathrm{y})=\max \{\mu(\mathrm{x}), \beta(\mathrm{y})\}<\beta(0)=$ $(\mu \times \beta)(0,0)$ which is a contradiction. Hence (ii) holds.

(iii) Is by similar method to part (ii).

(iv) Suppose $\beta(0) \leq \beta(x)$ by (i), then form (iii) either $\mu(0) \leq \mu(\mathrm{x})$ or $\mu(0) \leq \beta(x)$ for all $x \in X$. If $\mu(0) \leq \beta(x)$, for any $x \in X$, then $(\mu \times \beta)(0, x)=$ $\max \{\mu(0), \beta(\mathrm{x})\}=\beta(\mathrm{x})$. Let $\left(\mathrm{x}_{1}, \mathrm{x}_{2}\right),\left(\mathrm{y}_{1}, \mathrm{y}_{2}\right)$, $\left(\mathrm{z}_{1}, \mathrm{z}_{2}\right) \in \mathrm{X} \times \mathrm{X}$, since $(\mu \times \beta)$ is an anti-fuzzy

AT-ideal of $\mathrm{X} \times \mathrm{X}$, we have $(\mu \times \beta)\left(\mathrm{x}_{1} * \mathrm{z}_{1}, \mathrm{x}_{2} * \mathrm{z}_{2}\right) \leq \max \left\{(\mu \times \beta)\left(\left(\mathrm{x}_{1} *\left(\mathrm{y}_{1} * \mathrm{z}_{1}\right)\right),\left(\mathrm{x}_{2} *\left(\mathrm{y}_{2} *\right.\right.\right.\right.$

$$
\left.\left.\left.\left.\mathrm{z}_{2}\right)\right)\right),(\mu \times \beta)\left(\mathrm{y}_{1}, \mathrm{y}_{2}\right)\right\}----(\mathrm{A})
$$

If we take $\mathrm{x}_{1}=\mathrm{y}_{1}=\mathrm{z}_{1}=0$, then $\beta\left(\mathrm{x}_{2} * \mathrm{z}_{2}\right)=(\mu \times \beta)\left(0, \mathrm{x}_{2} * \mathrm{z}_{2}\right)$

$$
\begin{gathered}
\leq \max \left\{(\mu \times \beta)\left(0,\left(\mathrm{x}_{2} *\left(\mathrm{y}_{2} * \mathrm{z}_{2}\right)\right)\right),(\mu \times \beta)\left(0, \mathrm{y}_{2}\right)\right\} \\
=\max \left\{\max \left\{\mu(0), \beta\left(\left(\mathrm{x}_{2} *\left(\mathrm{y}_{2} * \mathrm{z}_{2}\right)\right)\right)\right\},\right. \\
\left.\max \left\{\mu(0), \beta\left(\mathrm{y}_{2}\right)\right\}\right\} \\
=\max \left\{\beta\left(\left(\mathrm{x}_{2} *\left(\mathrm{y}_{2} * \mathrm{z}_{2}\right)\right)\right), \beta\left(\mathrm{y}_{2}\right)\right\}
\end{gathered}
$$

This prove that $\beta$ is an anti - fuzzy AT - ideal of X .

Now we consider the case $\mu(0) \leq \mu(\mathrm{x})$ for all $\mathrm{x} \in \mathrm{X}$.

Suppose that $\mu(0)>\mu(y)$ for some $y \in X$. then $\beta(0) \leq \beta(y)<\mu(0)$.

Since $\mu(0) \leq \mu(\mathrm{x})$ for all $\mathrm{x} \in \mathrm{X}$, it follows that $\beta(0)$ $<\mu(\mathrm{x})$ for any $\mathrm{x} \in \mathrm{X}$.

Hence $(\mu \times \beta)(x, 0)=\max \{\mu(x), \beta(0)\}=\mu(x)$

taking $\mathrm{x}_{2}=\mathrm{y}_{2}=\mathrm{z}_{2}=0$ in (A), then

$$
\begin{gathered}
\mu\left(\mathrm{x}_{1} * \mathrm{z}_{1}\right)=(\mu \times \beta)\left(\mathrm{x}_{1} * \mathrm{z}_{1}, 0\right) \\
\leq \max \left\{(\mu \times \beta)\left(\left(\mathrm{x}_{1} *\left(\mathrm{y}_{1} * \mathrm{z}_{1}\right)\right), 0\right),(\mu \times \beta)\left(\mathrm{y}_{1}, 0\right)\right\} \\
=\max \left\{\max \left\{\mu\left(\mathrm{x}_{1} *\left(\mathrm{y}_{1} * \mathrm{z}_{1}\right)\right), \beta(0)\right\},\right. \\
\left.\max \left\{\mu\left(\mathrm{y}_{1}\right), \beta(0)\right\}\right\} \\
=\max \left\{\mu\left(\mathrm{x}_{1} *\left(\mathrm{y}_{1} * \mathrm{z}_{1}\right)\right), \mu\left(\mathrm{y}_{1}\right)\right\}
\end{gathered}
$$

Which proves that $\mu$ is an anti - fuzzy AT ideal of $X$. Hence either $\mu$ or $\beta$ is an anti fuzzy AT - ideal of X . $\triangle$

Theorem 6.12. Let $\beta$ be a fuzzy subset of an AT - algebra $X$ and let $R_{\beta}$ be the strongest fuzzy relation on $X$, then $\beta$ is an anti fuzzy AT - ideal of X if and only if $R_{\beta}$ is an anti - fuzzy AT - ideal of $\mathrm{X} \times \mathrm{X}$.

Proof: Assume that $\beta$ is an anti - fuzzy AT ideal of $X$. By proposition (6.7), we get, $R_{\beta}(0,0) \leq$ $\mathrm{R}_{\beta}(\mathrm{x}, \mathrm{y})$, for any $(\mathrm{x}, \mathrm{y}) \in \mathrm{X} \times \mathrm{X}$.

Let $\left(\mathrm{x}_{1}, \mathrm{x}_{2}\right),\left(\mathrm{y}_{1}, \mathrm{y}_{2}\right),\left(\mathrm{z}_{1}, \mathrm{z}_{2}\right) \in \mathrm{X} \times \mathrm{X}$, we have from $\left(\mathrm{AAT}_{2}\right)$ : 
Areej .T/Ahmed .H/Baieda .H

$$
\begin{aligned}
& \mathrm{R}_{\beta}\left(\mathrm{z}_{1} * \mathrm{x}_{1}, \mathrm{z}_{2} * \mathrm{x}_{2}\right)=\max \left\{\beta\left(\mathrm{z}_{1} * \mathrm{x}_{1}\right), \beta\left(\mathrm{z}_{2} * \mathrm{x}_{2}\right)\right\} \\
& \leq \max \left\{\max \left\{\beta\left(\mathrm{z}_{1} *\left(\mathrm{y}_{1} * \mathrm{x}_{1}\right)\right), \beta\left(\mathrm{y}_{1}\right)\right\}, \max \left\{\beta \left(\mathrm{z}_{2} *\right.\right.\right. \\
& \left.\left.\left.\left(\mathrm{y}_{2} * \mathrm{x}_{2}\right)\right), \beta\left(\mathrm{y}_{2}\right)\right\}\right\} \\
& \quad=\max \left\{\operatorname { m a x } \left\{\beta\left(\mathrm{z}_{1} *\left(\mathrm{y}_{1} * \mathrm{x}_{1}\right)\right), \beta\left(\mathrm{z}_{2} *\right.\right.\right. \\
& \left.\left.\left.\left(\mathrm{y}_{2} * \mathrm{x}_{2}\right)\right)\right\}, \max \left\{\beta\left(\mathrm{y}_{1}\right), \beta\left(\mathrm{y}_{2}\right)\right\}\right\} \\
& \quad=\max \left\{\mathrm{R}_{\beta}\left(\left(\mathrm{z}_{2} *\left(\mathrm{y}_{2} * \mathrm{x}_{2}\right)\right),\left(\mathrm{z}_{2} *\left(\mathrm{y}_{2} * \mathrm{x}_{2}\right)\right)\right),\right. \\
& \left.\mathrm{R}_{\beta}\left(\mathrm{y}_{1}, \mathrm{y}_{2}\right)\right\}
\end{aligned}
$$

Hence $\mathrm{R}_{\beta}$ is an anti - fuzzy AT - ideal of

$$
\mathrm{X} \times \mathrm{X}
$$

Conversely, suppose that $\mathbf{R}_{\beta}$ is an anti -

fuzzy AT - ideal of $\mathrm{X} \times \mathrm{X}$, by proposition

$(6.8) \beta(0) \leq \beta(x)$ for all $x \in X$, which prove $\left(\mathrm{AAT}_{1}\right)$.

$$
\text { Now, let }\left(\mathrm{x}_{1}, \mathrm{x}_{2}\right),\left(\mathrm{y}_{1}, \mathrm{y}_{2}\right),\left(\mathrm{z}_{1}, \mathrm{z}_{2}\right) \in \mathrm{X} \times \mathrm{X} \text {. }
$$

Then,

$$
\begin{aligned}
& \max \left\{\beta\left(\mathrm{z}_{1} * \mathrm{x}_{1}\right), \beta\left(\mathrm{z}_{2} * \mathrm{x}_{2}\right)\right\}=\mathrm{R}_{\beta}\left(\mathrm{z}_{1} * \mathrm{x}_{1}, \mathrm{z}_{2} *\right. \\
& \left.\mathrm{x}_{2}\right) \\
& \leq \max \left\{\mathrm { R } _ { \beta } \left(\left(\mathrm{z}_{1}, \mathrm{z}_{2}\right) *\left(\left(\mathrm{y}_{1}, \mathrm{y}_{2}\right) *\left(\mathrm{x}_{1}, \mathrm{x}_{2}\right)\right), \mathrm{R}_{\beta}\right.\right. \\
& \left.\left(\mathrm{y}_{1}, \mathrm{y}_{2}\right)\right\} \\
& \quad=\max \left\{\mathrm { R } _ { \beta } \left(\left(\mathrm{z}_{1} *\left(\mathrm{y}_{1} * \mathrm{x}_{1}\right)\right),\left(\mathrm{z}_{2} *\right.\right.\right. \\
& \left.\left.\left.\left(\mathrm{y}_{2} * \mathrm{x}_{2}\right)\right)\right), \mathrm{R}_{\beta}\left(\mathrm{y}_{1}, \mathrm{y}_{2}\right)\right\} \\
& \quad=\max \left\{\operatorname { m a x } \left\{\beta \left(\left(\mathrm{z}_{1} *\left(\mathrm{y}_{1} * \mathrm{x}_{1}\right)\right), \beta\left(\mathrm{z}_{2} *\right.\right.\right.\right. \\
& \left.\left.\left.\left(\mathrm{y}_{2} * \mathrm{x}_{2}\right)\right)\right\}, \max \left\{\beta\left(\mathrm{y}_{1}\right), \beta\left(\mathrm{y}_{2}\right)\right\}\right\}
\end{aligned}
$$

In particular if we take $\mathrm{x}_{2}=\mathrm{y}_{2}=\mathrm{z}_{2}=0$, then $\beta\left(\mathrm{z}_{1} * \mathrm{x}_{1}\right) \leq \max \left\{\beta\left(\mathrm{z}_{1} *\left(\mathrm{y}_{1} * \mathrm{x}_{1}\right)\right), \beta\left(\mathrm{y}_{1}\right)\right\}$.This proves $\left(\mathrm{AAT}_{2}\right)$ and $\beta$ is an anti - fuzzy AT - ideal of $\mathrm{X}$. $\triangle$

\section{References}

[1] Bhattacharye P. and MukherieeN.P. , Fuzzy relations and fuzzy group, Inform Sci. ,vol. 36 (1985), 267-282 .

[2] Dudek W. A., The number of sub-algebras of finite BCC-algebras, Bull. Inst. Math. Academia Sinica 20 (1992), 129-136.

[3] Hameed A. T., On (Fuzzy) AT-ideals of ATalgebras. Submitted.

[4] Is'ekiK. and Yanaka S., An introduction to theory of BCK-algebras, Math. Japonica, vol. 23 (1979), 1-20.

[5] Jun Y. B., Hong S. M. and Roh E. H., Fuzzy characteristic sub-algebras /ideals of a BCKalgebra, Pusan Kyongnam Math. J.(presentlyEast Asian Math. J.), vol. 9 , no.1 (1993), 127-132.

[6] Komori Y., The class of BCC-algebras is not a variety, Math. Japon., vol. 29 (1984), 391-394.

[7] Meng J. and Jun Y. B., BCK-algebras, Kyung Moon Sa Co., Korea, 1994.

[8] Mostafa S.M.,Hameed A. T. and Abed A. H. , Fuzzy KUS-Ideals of KUS-Algebras, Basra, Journal of Science (A), vol.34, no.2, pp:73-84, (2016) .

[9] Mostafa S.M.and Hameed A. T. , Anti-fuzzy KUS-ideals of KUS-algebras,International Journal of Computer Applications (0975 8887) Vol. 70, no.9 (2013), 24-28.

[10] Prabpayak C. and Leerawat U., On ideals and congurences in KU-algebras, Scientia Magna J. , vol. 5 , no.1 (2009), 54-57.

[11] Prabpayak C. and Leerawat U., On isomorphisms of $\mathrm{KU}$-algebras, Scientia Magna J., vol. 5 , no.3 (2009), 25-31.

[12] Xi O. G., Fuzzy BCK-algebras, Math. Japan., vol. 36(1991), 935-942.

[13] Zadeh L. A., Fuzzy sets, Inform. Control,vol.8 (1965), 338-353. 


$$
\begin{aligned}
& \text { المثاليات الضبابية المضاد (AT) في الجبريات (AT) }
\end{aligned}
$$

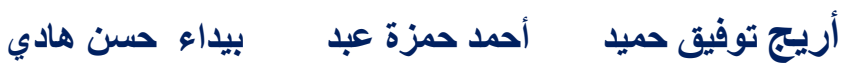

$$
\begin{aligned}
& \text { قسم الرياضيات، كلية التربية للبنات ، جامعة الكوفة ، العراق. }
\end{aligned}
$$

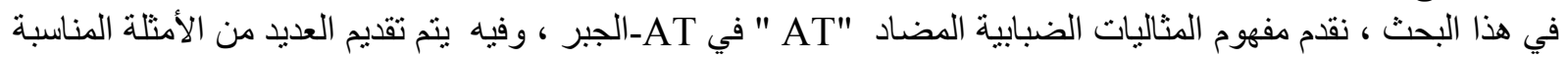

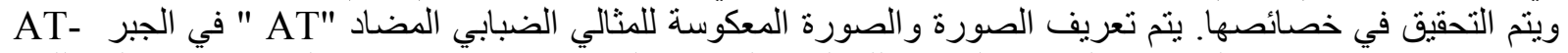

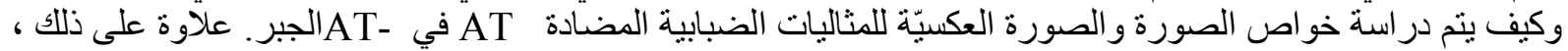

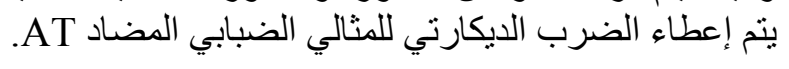

